\title{
ORIENTAÇÕES MINISTRADAS À GESTANTE DURANTE A ASSISTENCIA PRÉ-NATAL: atuação dos profissionais de Enfermagem
}

\author{
Yolanda Dora Martinez Évora* \\ Neide Fávero** \\ Maria A uxiliadora Trevisan** \\ Janete Rodrigues da S. Nakao***
}

EVORA, Y.D.M. et alii. Orientaçoes ministradas à gestante durante a assistência pré-natal: atu ação dos profissionais de enfermagem. Rev. Esc. Enf. USP, São Paulo, 22 (3) : 339-351, dez. 1988.

Para caracterizar as açōes educativas da enfermagem no Ambulatório de Pré-natal de um Hos. pital-escola, realizou-se um estudo fundamentado no levantamento retrospectivo das orientaços de enfermagem registradas nos prontú́rios médicos e na observagáo das mesmas ministradas pelos profissionais de enfermagem.

UNITERMOS: Enfermagem obstétrica. Cuidados pré-natal. Gravidez.

\section{INTRODUÇÃO}

Observa-se, no campo da saúde, que a educação é um processo, pelo qual se partilham conhecimentos, atitudes, valores, crenças e práticas; busca-se motivar e estimular o indivíduo a melhorar a sua saúde pelo próprio esforço, levando-se em conta o meio ambiente em que vive, bem como a sua individualidade ${ }^{7,15,21}$.

ALVIM" comenta que "o trabalho educativo do paciente e da familia é um processo contínuo que só poderá ser bem sucedido se houver uma ação conjunta entre os serviços comumente chamados de saúde pública e os serviços hospitalares", uma vez que a continuidade do cuidado de enfermagem depende de bom relacionamento, comunicação e cooperação dentro da própria equipe de saúde.

Os altos coeficientes de mortalidade neonatal devidos a causas perinatais sugerem, claramente, uma situação bastante desfavorável no tocante à assistência pré-natal, ao parto e ao recém-nascido. De fato, PUFFER e SERRANO ${ }^{18}$ mostraram cabalmente que a maioria das causas perinatais responsáveis pela alta mortalidade neonatal são evitáveis se houver adequada assistência pré-natal. Como ressaltam ANDRIASOLA et aliii ${ }^{3}$, esta mortalidade, passível de prevenção, é proveniente da deficiente atenção a saúde materna, tanto na assistência ambulatorial como na hospitalar. Maior e melhor assistência a gestantes, parturientes e recém-nascidos, acompanhada de adequada orientação

* Professor-Assistente do Departamento de Enfermagem Geral e Especializada da Escola de Enfermagem de Ribeirão Preto - USP.

** Professor-Assistente Doutor do Departamento de Enfermagem Geral e Especializada da Escola de Enfermagem de Ribeirão Preto - USP.

*** Auxiliar de Ensino do Departamento de Enfermagem Geral e Especializada da Escola de Enfermagem de Ribeirão Preto - USP. 
dada no período gestacional, poderiam seguramente, permitir redução sensível do número de óbitos pelas causas consideradas evitáveis ${ }^{3,5,14,18}$.

Partindo da filosofia de que a equipe de enfermagem não deve medir esforços no sentido de prestar assistência adequada aos pacientes, torna-se prioridade máxima, o ensino de conhecimentos fundamentais para assegurar a saúde do binômio mãe-filho, principalmente na assistência ambulatorial. O período gestacional é um período especial da vida da mulher, requerendo, portanto, cuidadoso trabalho educativo.

Com a finalidade de promover mudanças básicas na sistematização das ações educativas da enfermagem, o presente trabalho tem os seguintes objetivos:

- Fazer um estudo descritivo e analítico das anotaçðes de enfermagem registradas no prontuário medico, relativas às orientaçð̃es ministradas às gestantes no período pré-natal, pelos profissionais de enfermagem;

- Verificar se o conteúdo das orientaçðes verbais dadas aos clientes pelos profissionais de enfermagem são registradas nos prontuários médicos.

\section{MATERIAL E MÉTODO}

A presente pesquisa foi realizada no Hospital das Clínicas da Faculdade de Medicina de Ribeirão Preto da Universidade de São Paulo e constou de duas etapas distintas: a primeira consistiu no levantamento retrospectivo das orientaçōes de enfermagem registradas nos prontuários médicos durante um período de seis anos e a segunda, na observação das orientações dadas na pos-consulta de enfermagem, num período de 30 (trinta) dias.

\section{Primeira etapa}

\subsection{População}

A população estudada nesta etapa foi de 412 prontuários médicos das gestantes atendidas no Ambulatório de Pré-Natal no período de 1978 a 1983.

\subsection{Tamanho da amostra}

Com base no fichário de registro do Serviço de Arquivo Médico e Estatística (SAME), foi feita uma listagem dos números dos prontuários médicos pertencéntes a todas as gestantes que iniciaram a assistência pré-natal no período de 1978 a 1983 .

Para o sorteio da amostra foi utilizada uma calculadora Hewlett-Packard (HP-97), com um programa idealizado por $\mathrm{KNUTH}^{12}$. Os 7.111 números de registros dos prontuários médicos obedeceram ao método de amostragem casual simples, sem reposição.

A determinação do tamanho $n$ da amostra foi feita utilizando-se a expressão de WARWICK e LININGER ${ }^{23}$, tendo sido obtido no valor $n=412$. 


\subsection{Registro das Orientaçōes de Enfermagem}

De acordo com a disponibilidade de tempo dos pesquisadores, procedeu-se à consulta aos prontuários médicos no SAME da instituição em estudo. Para a transcrição das informaçðes contidas sobre as orientaçðes de enfermagem dadas no Ambulatório de Pré-Natal, utilizou-se um formulário padronizado.

\section{Segunda etapa}

\subsection{População}

A população estudada nesta etapa foi de 7 (sete) profissionais e ocupacionais de enfermagem, assim distribuídos: 1 (um) técnico de enfermagem; 3 (três) auxiliares de enfermagem; 2 (dois) atendentes e 1 (um) enfermeiro.

\subsection{Observação das orientações ministradas na Sala de Pós-Consulta de enfermagem}

A observação realizada das 8 ds 12 horas, foi do tipo estruturada, individual e não participativa (ANDER-EGG) ${ }^{2}$ com anotação simultânea em impresso próprio.

Para esta observação o observador permaneceu, ininterruptamente, na sala de PósConsulta de Enfermagem, a fim de observar as orientações dadas à gestante após a consulta médica.

Ao término de cada período de observação, o pesquisador checava se as anotaçð̄es registradas no prontuário medico correspondiam aquelas ministradas por ocasião da pós-consulta de enfermagem.

Foram feitas 79 observaçбes, relativas a 5,03\% do total de gestantes normais atendidas no Ambulatório de Pré-natal durante o ano em estudo.

\section{RESULTADOS E DISCUSSÃO}

As Figuras 1, 2, 3 e 4 mostram as orientaçбes dadas na Pós-consulta de enfermagem, segundo a idade gestacional.

Observa-se que, no primeiro trimestre da gravidez, as orientaçðes ministradas com maior frequência foram, respectivamente, no 20 e 30 meses (figura 1) sobre: folheto entregue a cliente com INSTRUÇÃO PARA GESTANTE (Anexo I), 25,7\% e 22,4\%; RETORNO, 21,7\% e 25,7\%; EXAMES DE ROTINA, 22,7\% e 22,0\% e IMPORTÂNCIA DO PRE-NATAL, $11,6 \%$ e $9,7 \%$. As demais orientaçðes neste trimestre tiveram pouco significado, de acordo com os baixos percentuais, encontrados.

Para o segundo trimestre (Figura 2) as orientaçoes mais frequentes foram, respectivamente: RETORNO, 37,5\% e 43,2\% e $41.3 \%$ : EXAMES DE ROTINA, 16,7\%, $15,9 \%$ e $16,0 \%$ e PRESCRIÇÃO MEDICA, 14,8\%, 14.6\% e 13,5\%. No 4 ? mês de gestação observou-se, ainda, elevado percentual $(13,2 \%)$ de entrega do folheto sobre INSTRUÇÃO PARA GESTANTE (Anexo I), que veio a decrescer no $5 \circ$ e $60^{\circ}$ meses $(5,2 \%$ e $6,0 \%$ ). Quanto à orientação sobre VACINA ANTITETÁNICA, recomendada pelo Ministério da Saúde a partir do 50 mês gestacional, observou-se que no 4 ọ mês 
houve um percentual pequeno de orientaçăo $(1,7 \%)$, seguido, no 5 9 mês, por $6,5 \%$ e aumentado, no 6 ? mês para $12,4 \%$ das orientaçסes.
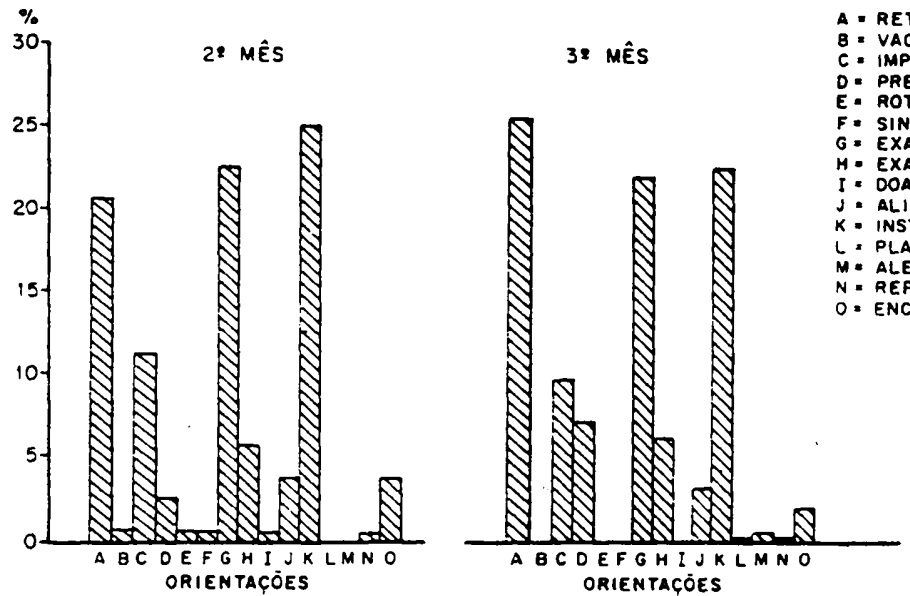

Fig. 1-DISTRIBUIÇĀo PERCENTUAL DAS ORIENTAÇÖES MINISTRADAS ÀS GESTANTES

NO PRIMEIRO TRIMESTRE GESTACIONAL, NO PERÍODO DE 1978 a 1983.

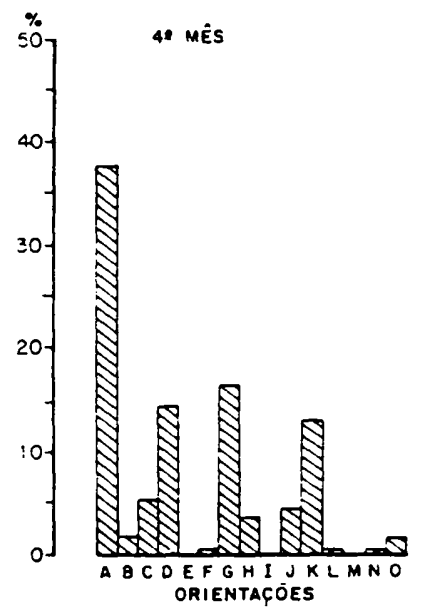

5. MÉS

6ะ MÊS

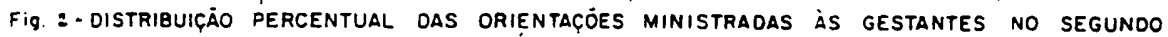
TRIMESTRE GESTACIONAL. NO PERIODO OE 1978 A 1983.

Para o terceiro trimestre (Figura 3) as orientaçбes mais encontradas foram respectivamente, no $19,2 \%$ e 39 mes (do trimestre), RETORNO, 40,5\%, 40,2\% e 40,5\%; VACINA, $15,8 \%, 13,5 \%$ e 7,3\%; PRESCRIÇÃO MEDICA, $11,3 \%, 9,3 \%$ e 9,5\%; EXAMES DE ROTINA apresentou um percentual elevado no $7 \%$ e 8 ? mêses de gravidez $(10,7 \%$ e $9,1 \%)$, decrescendo no 9 9 mês $(4,2 \%)$. A Figura 4 mostra estes achados, numa visão global das orientaçð̄es.

Convém ressaltar que a pós-consulta é uma atividade a ser executada especialmente após a consulta médica e consiste no reforço das orientaçós dada do médico quanto à consulta e a prescrição médica, bem como quanto aos cuidados com a saúde 


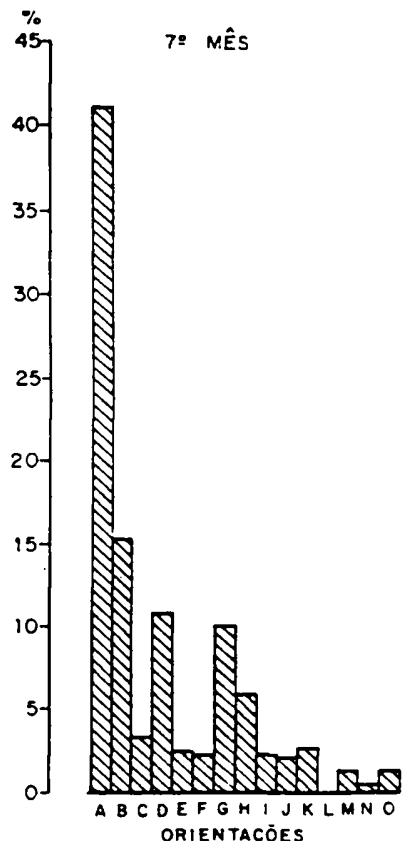

8 MÊS

9? MÉS
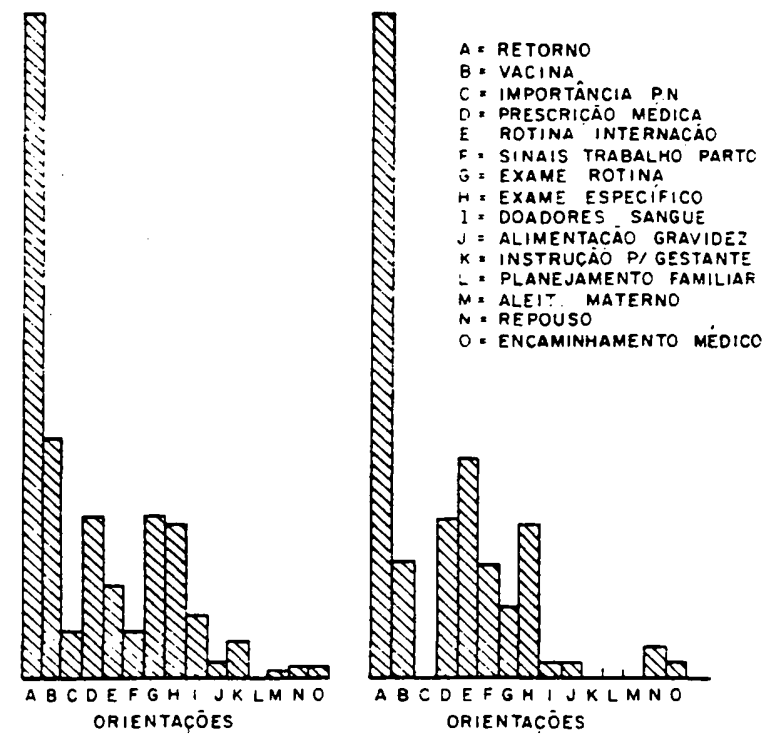

Fig. 3 - DISTRIBUICĀo PERCENTUAL DAS ORIENTACÓES, MINISTRADAS TERCEIRO TRIMESTRE GESTACIONAL, NO PERIODO DE 1978

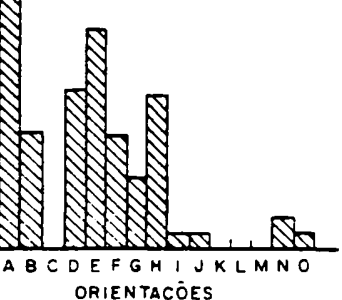

AS GESTANTES NO A 1983
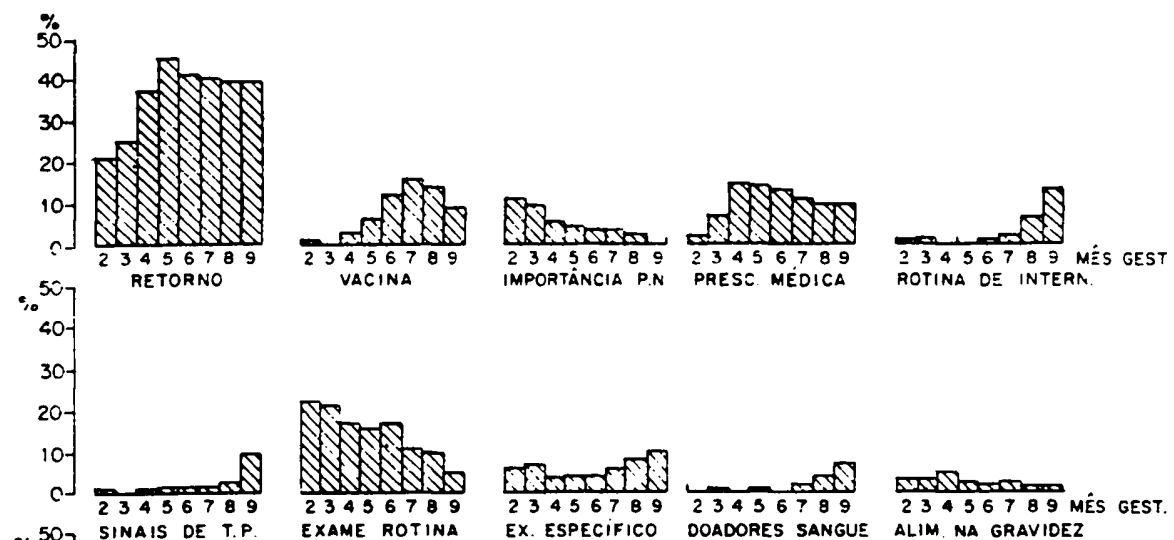

23456789 MÉS GEST.

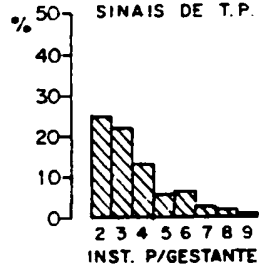

EXAME ROTINA

EX. ESPECIFICO

DOAD 45 ? 99

ALIM. NA GRAVIDEZ

Fig. DISTRIBUIÇÃO DAS ORIENTAÇÖES MINISTRADAS AS gESTANTES NA POS-CONSULTA DE ENFERMAGEM SEGUNDO O MËS GESTACIONAL, NO PERIODO DE 1978 A 1983. 
e ao encaminhamento do paciente para outras atividades desenvolvidas no Ambulatório. Seus objetivos básicos são interpretar, para o paciente, as alternativas:de execução das orientaçðes médicas e ordenar da melhor forma possível as demais atividades a ele acessiveis ${ }^{6}$.

Em face dos resultados encontrados neste estudo retrospectivo, toma-se difícil julgar a qualidade das orientaçбes ministradas ds gestantes, uma vez que os dados foram obtidos por meio das anotações registradas no prontuário médico.

Não se pode negar a existência do objetivo do pessoal de enfermagem e a seus bons propósitos de educar; entretanto, observou-se uma prática rotineira e condicionadora, como se pode observar nos exemplos a seguir, transcritos dos prontuários médicos:

"12/05/79 - Orientado: vacina, exames de rotinas e retorno. I...(aux-enf)."

"27/05/80 - Orientado internação e doadores de sangue. N...(aux enf)."

"13/12/81 - Orientada quanto a exames de rotina, alimentação, encaminhamento médico e retorno. B... (aux-enf)"

"24/01/82 - Orientada quanto a prescrição médica e retomo. B... (aux enf)"

"24/04/83 - Orientada: importância do pré-natal e retorno. D...(tec-enf)"

"23/09/83 - Orientada quanto aos exames de rotina, retomo para resultado e importância do pré-natal. B... (aux enf)"

"11/10/83 - Orientada sobre internação e trabalho de parto, retomo. N... (aux enf)".

Diante destes exemplos, pode-se notar que os assuntos da orientação e a forma como foram registrados permaneceram constantes durante os seis anos do estudo. Tais anotaçбes realmente não demonstraram qualidade por serem imprecisas, inespecíficas e sem um conteúdo significativo que permita analisar o que realmente foi dito; além disso, não indicaram uma sequência de orientação, não objetivaram a situação da gestante, enfim, não revelaram um planejamento para atender ds necessidades de cada paciente em particular. Ressalta-se que em nenhum prontuário medico observou-se o registro da fala da gestante, tomando-se difícil inferir qualquer conceito de valor. Pelas anotações, pode-se afirmar que as pós-consultas de enfermagem estabeleceram-se na forma de monologos.

$\dot{E}$ opinião de vários autores ${ }^{4,11,13,16,17,22}$ que a comunicação escrita é uma importante fonte de informaçăo, podendo ser utilizada como documento legal e como subsídio para investigações. Além disso, propicia o desenvolvimento, a avaliação e o aprimoramento da assistência de enfermagem. No entanto, segundo SALZANO ${ }^{20}$, os estudos e a experiência sobre as anotaçðes de enfermagem mostram que, quase sempre, as anotaçð̄es têm se apresentado insuficientes e rudimentares, e que dados relevantes sobre o paciente não têm sido registrados. O presente estudo reforça o que diz este autor, pois observou-se que os registros de enfermagem no prontuário médico têm-se detido apenas em informaçð̄es pouco abrangentes, rotineiras e repetitivas; estas informaçðes normalmente so dizem respeito a conduta medica e raramente expressam as necessidades do paciente, não retratam um atendimento personalizado ou real assisténcia de enfermagem ao paciente.

Pode-se verificar atraves da literatura, que os profissionais e ocupacionais de enfermagem não têm o hábito de anotar o que fazem e/ou a orientação dada, e, quando o 
fazem, é sem a consciência da importância do registro bem feito das açð̃es que executam junto aos pacientes. Acresça-se ainda que, de modo geral, as anotaçōes de enfermagem são incompletas e não satisfazem aos requisitos necessários para a sua padronização $0^{4,16,19,22}$.

Como referem DUARTE et alii ${ }^{9}$, "há de se lamentar o fato de nós mesmos estarmos permitindo, pela falta de anotação ou pela qualidade de algumas, que não conste da documentação do paciente a unidade indicadora de nossas ações".

É importante salientar que não é suficiente apenas anotar. É necessário que o registro seja de boa qualidade, em linguagem compreensível e expresso de maneira inteligivel.

A Figura 5 representa a distribuição dos profissionais de enfermagem segundo a frequência de anotaçōes da orientação dada na pós-consulta no prontuário médico.

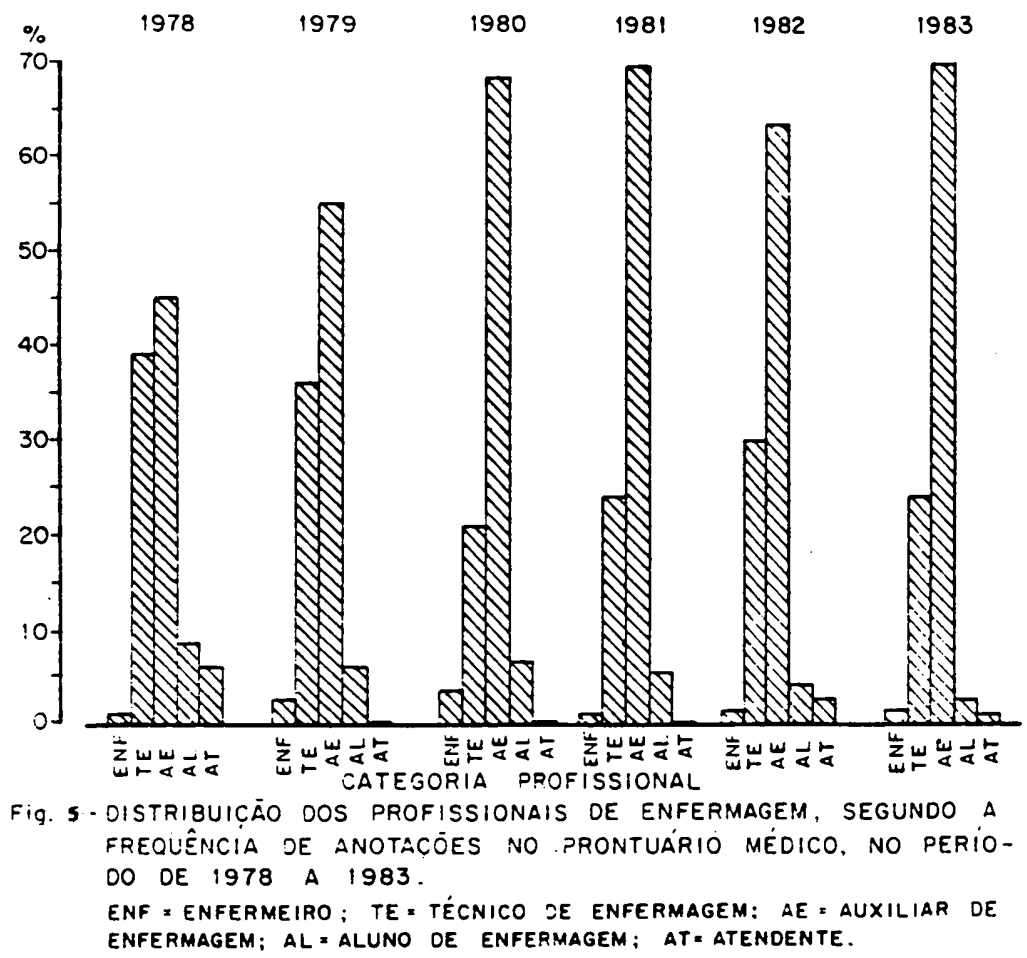

A análise desta Figura evidenciou que o maior número de orientações, 1028 $(64,6 \%)$, foi dado pelos auxiliares de enfermagem, seguido de $438(27,5 \%)$ dadas pelo técnico de enfermagem. Durante o período em estudo, o aluno de graduação em enfermagem realizou $79(5,0 \%)$ das orientaçסes, e a enfermeira apenas $24(1,5 \%)$.

Apesar de, na instituição estudada, não fazer parte das funçð̄es do atendente de enfermagem as orientações de pacientes na pós-consulta de enfermagem, esta atividade fez-se presente nos anos de 1978, 1982 e 1983 , tendo uma atendente orientado 23 pacientes ou dado informaçōes sobre os mesmos $(1,4 \%)$.

A Figura 5 mostra, ainda, que as orientaçðes ministradas pela enfermeira apesar 
de escassas, tiveram um aumento gradual em 1978, 1979 e 1980, decrescendo em 1981 e mantendo este percentual, com pequenas variações, nos anos de 1982 e 1983. Esta ausência marcante da enfermeira diante das atividades educativas junto à gestante é justificada por DANIEL ${ }^{8}$, quando diz que, no desempenho de sua profissão, a enfermeira vê-se na contingência de executar muitas atividades, como preencher a demanda de cargos administrativos, participar de atividades burocráticas, manipular eficientemente multiplos e complexos aparelhos, tudo em detrimento de sua verdadeira função. Acresça-se que a enfermeira, em virtude da complexidade e diversidade das funçốcs que the são confiadas, depara-se com a necessidade de delegar ao técnico ou auxiliar de enfermagem, sob sua supervisão, a responsabilidade das atividades educativas na pósconsulta de enfermagem.

A Tabela 1 mostra as orientaçð̃es ministradas às gestantes na primeira pós-consulta de enfermagem, segundo o conteúdo verbal e o conteúdo registrado no prontuário médico.

\section{TABELA 1}

ORIENTAÇÕES REALIZADAS A 79 GESTANTES POR OCASIÃO DA PRIMEIRA POS-CONSULTA DE ENFERMAGEM, SEGUNDO O CONTEÚDO VERBAL E O CONTEÚDO REGISTRADO NO PRONTUÁRIO MÉDICO. FREQUÉNCIA E PORCENTAGEM.

\begin{tabular}{l|rrrr}
\hline \multicolumn{1}{c|}{ Conteúdo } & \multicolumn{2}{c}{ Verbal } & \multicolumn{2}{c}{ Registrado } \\
Orientaçס̃es & No & $\%$ & No & $\%$ \\
\hline Retomno & 36 & 45,5 & 36 & 45,5 \\
Vacina & 21 & 26,6 & 22 & 27,8 \\
Importância do Pré-natal & 7 & 8,8 & 7 & 8,8 \\
Prescrição médica & 17 & 21,5 & 14 & 17,7 \\
Rotina de Internação & 2 & 2,5 & 2 & 2,5 \\
Sinais de Trabalho de Parto & 2 & 2,5 & 2 & 2,5 \\
Exames de Rotina & 77 & 97,5 & 77 & 97,5 \\
Exames Específicos & 7 & 8,8 & 7 & 8,8 \\
Doadores de Sangue & 2 & 2,5 & 2 & 2,5 \\
Alimentação na Gravidez & 4 & 5,0 & - & - \\
Instrução para Gestante * & 71 & 90,0 & 71 & 90,0 \\
Planejamento Familiar & 3 & 3,8 & 3 & 3,8 \\
Aleitamento Materno & 1 & 1,3 & - & - \\
Repouso & 2 & 2,5 & - & - \\
Encaminhamento Médico & 3 & 3,8 & 3 & 3,8 \\
Higienne Corporal & 1 & 1,3 & - & - \\
\hline
\end{tabular}

* Vide Anexo I.

Observou-se que houve pequena diferença de número das orientaçбes verbais e as registradas. Por outro lado, $25,0 \%$ dos assuntos abordados na pós-consulta deixaram de ser registrados no prontuário médico pelo profissional de enfermagem, constituindose em importante omissão de registro. A este respeito, FÁVERO ${ }^{10}$ realizou um estudc descritivo das anotaçōes de enfermagem de pacientes intemados no mesmo hospital escola govemamental em estudo. Comparando as observaçōes diretas das atividades de enfermagem e respectivas anotaçðes, constatou tamberm que, das atividades de enfer- 
magem executadas durante a investigação, quase a metade $(41,5 \%)$ não foi anotada no prontuário médico.

E importante ressaltar, que os assuntos referentes a RETORNO, EXAMES DE ROTINA e INSTRUÇÃO PARA GESTANTE (Anexo I) foram os mais mencionados, não tendo havido omissão de registro.

Dentre os outros assuntos, observou-se que a orientação sobre VACINA foi dada para 21 gestantes $(26,6 \%)$ e foi registrada para $22(27,8 \%)$, ocorrendo assim um registro sem que a orientação tivesse sido realizada. Isto talvez tenha ocorrido devido à "automatização" do profissional de enfermagem em anotar, no prontuário médico, as mesmas orientaçð̃es várias vezes ao dia. Acresça-se a isso, a ausência de privacidade total na Sala de Pós-consulta, que é utilizada por muitos profissionais da saúde como "passagem" para a parte de circulação intema do ambulatório, fato que não ocorre quando sé trata de um consultório médico.

Para a PRESCRIÇÃO MẼDICA, houve omissão de 3 registros $(3,8 \%)$ a menos no prontuário médico.

Com relação aos assuntos sobre ALIMENTAÇÃO NA GRAVIDEZ, ALEITAMENTO MATERNO, REPOUSO e HIGIENE CORPORAL observou-se que estes, algumas vezes, foram mencionados verbalmente sem serem registrados, respectivamente em $4(5,0 \%) ; 2(2,5 \%)$ e $1(1,3 \%)$ observações.

Para os demais assuntos abordados, não houve qualquer tipo de omissão, pois, o que foi orientado verbalmente, foi registrado no prontuário médico.

Estas observaçoes concordam com RIBEIRO ${ }^{19}$, ou seja, a inexistência de uma sistemática precisa, que oriente e determine um padrão do que deve ser observado e anotado pela enfermagem, acarreta a elaboração de registros incompletos, sem conteúdo significativo, e muitas vezes contendo informaçōes não condizentes com a realidade.

\section{CONCLUSÕES}

A partir dos resultados obtidos podem ser tiradas as conclusð̃es que seguem:

- A análise das orientações ministradas na pós-consulta de enfermagem, de acordo com os trimestres gestacionais, demonstrou que as açðes educativas junto ds gestantes, raramente foram satisfatórias, observando-se uma prática rotineira e condicionadora. Foi verificado que os assuntos orientados e a forma como foram registrados permaneceram constantes durante a investigação.

- As anotaçðes de enfermagem apresentaram-se imprecisas, inespecíficas e sem conteúdo significativo que permita a análise do que realmente foi dito.

- Diante dos resultados encontrados no estudo retrospectivo, conclui-se que uma investigação embasada somente etn registros de enfermagem no prontuário médico não reflete a realidade, podendo até fornecer uma visão distorcida das orientaçð̃es mi. nistrađas na pós-consulta.

- O desempenho dos profissionais de enfermagem não foi satisfatório, evidenciando-se a ministração de orientaçós sumárias, impessoais e fragmentadas, como uma rotina de trabalho. 
ÉVORA, Y.D.M. et alii. Orientation fiven to the pregnant women during prenatal care: performance of nursing professionals. Rev. Esc. Enf. USP, São Paulo, 22 (3):339-351, dec. 1988.

To characterize the educational mursing actions at the Prenatal Care Outpatients Clinic of the University Hospital, Faculty of Medicine of Ribeirao Preto, University of Säo Paub, it was carried out a study based on a retrospective survey of mursing notes made on medical records and an obser. vation of the guidance provided by the mursing professional.

UNITERMS: Obstetrical nursing. Prenatal care. Pregnancy.

\section{REFERẼNCIAS BIBLIOGRÁFICAS}

1. ALVIM, E.F. Considerações sobre o trabalho educativo num sistema médio-sanitário educativo. Rev. Bras. Enf., Brasília, 8 (3): 206-14, set., 1955.

2. ANDER-EGG, E. Introdución a las tecnicas de investigación social. 5.ed. Buenos Aires, ECRO, 1976. p. 95-124.

3. ANDRIASOLA, G. et alii. Insuficiência del control pré-natal sobre la morbimortalidad materna y perinatal. Bol. Of. Sanit. Panamer., Washington, 83 (5): 413-24, nov. 1977.

4. ANGERAMI, E.L.S. et alii. Análise crítica das anotações de enfermagem. Rev. Bras. Enf., Brasília, 29 (4): 28-37, out./dez. 1976.

5. BELFORT, P. Assistência pré-natal. In: REZENDE, J. Obstetrícia. 3.ed. Rio de Janeiro, Guanabara - Koogan, 1974. Cap. 10. p. 222-42.

6. BRASIL. Ministério da Saúde. Programa de Saúde Materno-Infantil. Coordenação de proteção infantil da Secretaria de Assistência Médica. Brasília, 1975.

7. CURI, L.F. et alii. Influência da orientação no pré-natal no comportamento das parturientes. Enf. Atual., Rio de Janeiro, 2 (10): 24-15, mar/abr. 1980.

8. DANIEL, F.L. A enfermagem planejada. 3.ed. São Paulo, EPU, 1981. 135 p.

9. DUARTE, A.B. et alii. Importância das anotações dos cuidados de enfermagem. Rev. Bras. Enf., Brasília, 29 (3): 83-91, Jul./Set., 1976.

10. FÁVERO, N. Estudo das anotações de enfermagem na assistência direta ao paciente. Ribeirão Preto, 1979. (Disser tação de mestrado - Escola de Enfermagem de Ribeirão Pre to da USP).

11. FÁVERO, N. et alii. A importância da comunicação como instrumento aḍministrativo: especial referência à anotação de enfermagem. Rev. Paul. Hospitais, São Paulo, 31 (1/2): 4-7, jan./fev. 1983.

12. KNUTH, D.E. The art of computer programming. Reading, Addison-Wesley, 1971, v. 2.

13. KURCGANT, P. Auditoria em enfermagem. Rev. Bras. Enf., Brasília 29 (3): 106-24, jul./set. 1976.

14. MARTINEZ, A.R. Conduta na assistência pré-natal. Atual Méd. São Paulo, 9 (1): 20, abril, 1973.

15. NEVES, S.T. Educação em saúde no hospital. Rev. Paül. Hosp., São Paulo, 29 (8): 227-33, ago, 1981.

16. OGUISSO, T. Os aspectos legais da anotação de enfermagem no prontuário do paciente. (Tese de livre docência - Escola de Enfermagem Ana Neri da UFRJ), 1975. 120 p.

17. PAIM, L. Plano assistencial e prescriçōes de enfermagem. Rev. Bras. Enf., Rio de Janeiro, 29 (3): 66-82, jul./set. 1976.

18. PUFFER, R.R. \& SERRANO, C.V. Características de la mortalidad en la niñez. Washington, Organización Panamericana de la Salud, 1973. 499 p.

19. RIBEIRO, C.M. Atividades de enfermagem de Saúde Pública no hospital: estruturas organizacionais que favorecem o desenvolvimento dessas atividades. Rev. Bras. Enf., Rio de Janeiro, $15(1 / 2): 81-88$, jan./abr. 1972. 
20. SALZANO, S.D.T. Instrumento de comunicação de enfermagem: estudo da implantação de um modelo de comunicação escrita entre as equipes de enfermagem das unidades cirúrgicas e do centro cirúrgico. Rev. Esc. Enf. USP., São Paulo, 17 (3): 235-452, dez. 1983.

21. SoUZA, M.N. A educação em saúde nos hospitais. Rev. Paul. Hosp., São Paulo, 32 (7/8): 167-71, jul./ago. 1984.

22. VIEIRA, A. et alii. O princípio da investigação e observação na enfermagem: uma experiência em um hospital escola. Rev. Bras. Enf., Rio de Janeiro 24 (5): 66-89, jul./set., 1971.

23. WARWICK, D.P. \& LININGER, C.A. The sample survey: theory and practice. New York, McGraw-Hill Book, 1975. 


\section{ANEXO I}

\section{HOSPITAL DAS CLINICAS DA FACULDADE DE MEDICINA DE RIBEIRÃO PRETO DA UNIVERSIDADE DE SÃO PAULO}

\section{AMBULATORIO DE CLINICA OBSTÉTRICA \\ - Instruções para gestantes -}

1. A gravidez é um período importante para a senhora e para o bebê. Ele precisa se formar, crescer e ficar forte, usando aquilo que a senhora come e bebe. Precisa, também, eliminar o que não aproveita e faz isto naturalmente através de sua pessoa. A mãe tratando-se, também tratará da criança.

2. Passeie ao ar livre (praças, jardins, bosque), evitando as subidas, não carregue peso muito grande, não faça esforços violentos.

3. Durma todas as noites 8 horas, em quarto bem ventilado, evitando corrente de ar. Procure dormir ou descansar um pouco durante o dia, com os pés mais altos que o resto do corpo.

4. Tome banho todos os dias. Os banhos devem ser de chuveiro ou caneca, evitando os banhos de assento.

5. Cuide de seus seios, lave-os diariamente, enxugue com pano limpo e passe uma pequena quantidade de vaselina ou óleo nos bicos. Mantenha-os limpos e, se notar alguma coisa diferente, procure o médico.

6. Evite a prisão de ventre. Coma frutas com bagaço, verduras, beba bastante água e procure evacuar em horas certas, todos os dias, pois, isto acostumará seu intestino a funcionar.

7. Beba todos os dias, quatro a cinco copos de água ou suco de frutas (limonada, laranjada, cajuada, etc.). pelo médico.

8. Não use cinta-liga no ventre ou nas pernas, a não ser quando recomendada

9. Procure beber, diariamente, um litro de leite. Coma, também, ovos, queijos, carne, miúdos de vaca, principalmente o fígado (ao menos três vezes por semana). Procure comêtos cozidos, evitando as frituras.

10. Lembre-se que as verduras e frutas frescas são as melhores, principalmente, se comidas cruas, porque fornecem vitaminas necessárias à senhora e ao bebê.

11. Se o médico mudar sua alimentação, obedeça-o; é para o seu próprio bem. É melhor evitar doenças que curá-las. 
12. Volte ao retomo marcado, conte ao médico toda anormalidade (dor de cabeça, dor de estômago, mancha de visão, inchaço, urina escura, formigamentos e câimbras) e, se estes incômodos forem fortes, volte antes do dia marcado.

13. Traga no dia seguinte da primeira consulta: urina em vidro bem limpo; fezes em uma lata limpa e venha em jejum para colher sangue (às 7:30 horas). Traga alguma fruta para comer após tirar o sangue.

14. Quando perder sangue pela vagina, fique na cama, beba água, suco de frutas e chame o pronto socorro ou procu re o médico imediatamente. o parto.

15. Não tenha relações sexuais durante o último mês de gravidez e nos $\mathbf{4 0}$ dias após

16. No fim da gravidez aparecem sinais que mostram que a criança vai nascer. Estes sinais são:

a) endurecimento repetido do ventre;

b) perda de catarro amarelo escuro pela vagina, às vezes, com gotas de sangue; $\mathrm{e}$

c) perda de água pela vagina.

17. Estes sinais indicam que o parto começou; eles podem aparecer juntos ou separados e, logo que um deles aparecer, procure o médico ou o Hospital.

18. Compareça ao retomo após o parto, na data marcada. É muito importante para a senhora, mesmo que esteja se sentindo bem. 